\title{
Research Paper: The Effect of Visual and Tennis Training on Perceptual-Motor Skill and Learning of Forehand Drive in Table Tennis Players
}

\author{
Fahimeh Basiri $^{1}$ (D), Alireza Farsi ${ }^{* *}$ (D), Behrooz Abdoli ${ }^{1}$ (D), Maryam Kavyani' ${ }^{1}$ (D)
}

1. Department of Behavioral and Cognitive Sciences in Sport, Faculty of Sport Sciences and Health, Shahid Beheshti University, Tehran, Iran.

ctration: Basiri F, Farsi A, Abdoli B, Kavyani M. The Effect of Visual and Tennis Training on Perceptual-Motor Skill and Learning of Forehand Drive in Table Tennis Players. Journal of Modern Rehabilitation. 2020; 14(1):21-32. http://dx.doi. org/10.32598/JMR.14.1.3

http://dx.doi.org/10.32598/JMR.14.1.3

\section{Keywords:}

Depth perception, Anticipation, Decision making, Eye-hand coordination, Acquisition, Retention, Motor learning

\section{ABSTRACT}

Introduction: The present study was designed to investigate the effect of visual and skill training on learning forehand drive in table tennis and motor-perceptual abilities (reaction time, coincidence-anticipation timing, eye-hand coordination, and depth perception).

Materials and Methods: Forty volunteer female students (Mean \pm SD age: $21.50 \pm 0.78$ years) were selected and randomly assigned to one of four groups (each group had 10 participants): visual and tennis training group, visual training group, tennis training group, and control group. Motor perceptual abilities (reaction time, coincidence-anticipation timing, eye-hand coordination, and depth perception) and forehand drive performance were measured before and after the training period, and also after $24 \mathrm{~h}$ retention period. After the pretest, including the accuracy of the kicks test for assessment of forehand drive in table tennis and motorperceptual test, the experimental groups underwent four weeks (three sessions per week) of visual training, table tennis forehand training, or both. The control group followed their normal daily life for the whole study period. Then, they participated in the posttest and $24 \mathrm{~h}$ later in the retention test of kick accuracy.

Results: The results revealed that visual and table tennis training, visual training, and table tennis training had a significant effect on the reaction time $(\mathrm{P}=0.001)$, coincidence-anticipation timing $(\mathrm{P}=0.001)$ and eye-hand coordination (error time) $(\mathrm{P}=0.01)$. Moreover, visual and tennis training and table tennis training had a significant effect on the acquisition $(\mathrm{P}=0.001)$ and retention of forehand drive $(\mathrm{P}=0.005)$. Besides, the post hoc LSD (Least Significant Difference) test showed that visual and tennis training had a more significant impact on the learning forehand drive. Visual training and tennis training had a significant effect on eye-hand coordination (number of errors). The three types of training programs were not effective in the depth of perception.

Conclusion: Visual training can be used as a supplementary program in the athletes' training schedule.

\footnotetext{
* Corresponding Author:

Alireza Farsi, PhD.

Address: Department of Behavioral and Cognitive Sciences in Sport, Faculty of Sport Sciences and Health, Shahid Beheshti University, Tehran, Iran. Tel: +98 (912) 4471778

E-mail:arfarsi@gamil.com
} 


\section{Introduction}

A

mong all the five senses, humans have more tendency towards, and more reliance on sight $[1,2]$, and about $80 \%$ of the input received by our body is through vision [3]. Vision is one of the most important sensory systems involved in the performance of many sports skills. Vision in sports performances provides the ability to interpret the environmental information, body alignment, spatial orientation, balance, the timing of movement, response to stimuli, and anticipation. Christensen and Winkelstein stated that athletes require superior and advanced visual ability to succeed in their sports activities [4]. Moreover, it has been reported that athletes have better visual abilities than non-athletes $[5,6]$.

Some evidence suggests that the visual system, like other body systems, can also be improved through special visual training $[7,8]$. The visual system, such as the musculoskeletal system, responds to the overload principle. Even the perceptual components of the visual system can be improved by sports vision training [9, 10]. It also seems that stress or overloading can affect visual perceptual, visual motor, and visual perceptional systems during sports training and can provide better conditions to be prepared for the competition $[11,12]$. It has been also shown that visual training may lead to the development of brain regions related to vision, including visual memory, figure-ground perception, and orientation. Acquiring these capabilities help the athlete to use them efficiently in their sports $[9,13]$.

Although evidence supporting the effectiveness of visual training on sports performances is available, there are some contradictory findings. For example, Wood and Abernethy studied the effect of four weeks of visual training programs on sporting performance. The results showed that the effectiveness of visual training accompanied by physical training is not more than physical training alone [14]. In another research, Abernethy and Wood found the effect of two types of generalized visual training programs on athletes' visual and motor function in racquet sports, revealing that training did not improve either vision or motor performance [15].

On the other hand, West and Bressan reported that visual training might improve cricketer's performance [16]. Di Russo reported improvement in eye saccadic movements (the quick movement of the eyes by which the gaze is transferred from one fixation point to another) as a result of visual training [17]. Also, Tate and colleagues reported the positive impact of visual skills training on visual skills and sports performance in cricketers [9]. $\mathrm{du}$ Toit et al. reported that visual training improved performance and visual skills in hockey players [18]. The research by Hapwood indicates an improvement in the performance of skilled cricketers after field training and visual perceptual training [19].

In addition to the importance of vision and reaction to visual stimuli in sport and the undeniable role of visual training on sports performance, in a ball and racket sports such as table tennis that ball rushes in the space and athlete performs under time-constraints, vision plays a much more critical role than other senses [20]. Visual perception is one of the most important factors for successful performance. Table tennis, as such, is characterized by perceptual complexity and time pressure. To react to such a variable stimulus, the players need to have the ability to acquire an enormous amount of information about the impendent objects. For instance, hitting the ball requires continuous convergence of eyes, assessing the speed of the ball, predicting the ball path, rapid and saccadic movement of the eyes for the detection of ball position, the eye's ability to change the accommodative state (accommodative facility), ability to adjust hand and eye movements (eye-hand coordination) simultaneously, and detection of the ball at different speeds, ranges, and distances (visual reaction time) [1].

Also, in sports activities, a close relationship exists between perception and action. According to the actionperception theory, players should extract more valuable sources from visual information and then use this received information to trigger and initiate the motor system and produce appropriate reaction [21]. It seems that simultaneous attention to visual system training and motor system training is essential for learning and improvement in table tennis skills. The saccadic movements as visual training were selected because, in table tennis, rapid eye movement (saccadic movement) plays an essential role in gathering information from the environment.

Considering the importance of visual training on different sports skills, especially rocket sports, and the fact that during skill training, using other factors along with physical training is necessary and obvious. Therefore, in the present study, we investigate the effect of visual and skill training on motor-perceptual abilities (reaction time, coincidence-anticipation timing, eye-hand coordination, and depth perception) that seem to play an essential role in the table tennis and the forehand drive skill. We aim to determine whether the visual training alone improves the motor-perceptual abilities and the expertise of forehand 
drive. In other words, if the combination of visual and skill training has a better impact on these abilities and learning of sports skills.

\section{Materials and Methods}

\section{Study participants}

Forty volunteer female students (Mean \pm SD age: $21.50 \pm 0.78$ years) were selected and randomly assigned to four groups: combined visual and tennis training group (VT), visual training group (V), tennis training group (T), and control group (C). All participants had normal or corrected to normal vision with no experience in tennis. They were all right eyedness and handedness. Those volunteers with any musculoskeletal injuries or refractive errors were omitted from the study. All of them were inexperienced students who had not any experience in tennis. All participants in these experiments reported having normal or corrected to normal vision.

\section{Tools and measurements}

The study data were collected with the following tools:

\section{Snellen eye chart}

It was used to measure the visual acuity of the participants, and the regulation test was used to determine the dominant eye.

Bassin anticipation timer device (Lafayette Instrument Co., Model 35575)

It was used to measure coincidence-anticipation timing accuracy. The reliability of coincidence-anticipation timing accuracy was estimated using Guttman's $\lambda 2$. This estimate yielded values of 0.78 for the sum of correct and delayed responses. Construct validity can be assumed because the aspects of performance measured constitute the criteria for the construct of signal detection in accordance with signal detection theory. Studies with extreme groups also yielded excellent results.

\section{Vienna testing system}

In the current research, the double labyrinth test (B19) was used to measure eye-hand coordination. The variables evaluated in this test include the number of errors, the error time duration, and the percentage of error time duration for both hands, and for the right and left hands separately. For the double labyrinth test, the split-half reliability coefficients vary between 0.83 and 0.96 for respondents of different educational levels. Construct validity for the double labyrinth test has been demonstrated by correlation analysis. The content of the Double Labyrinth test is similar to the content of other tests that measure eye-hand coordination. This confirms the predictive validity of the present test

\section{Visual training protocol}

An arrow key was presented in white color against a dark grey background on a 19" CRT monitor connected to an Intel Core Duo processor. Stimuli were presented with a $57-\mathrm{cm}$ view distance. The program through which all stimuli were presented, and all manual responses were recorded by PsychoPy software.

Howard-Dolman apparatus (Lafayette Instrument Co, Model 14012c)

It was used to measure depth perception, which is the most common test instrument for measuring actual depth.

Reaction timer apparatus (Lafayette Instrument Co, Model 63035, Lafette)

It was used to measure choice reaction time. The timer records the time interval between the appearance of the stimulus and the response. The test was taken three times, and the mean reaction time was recorded as the final score.

Hitting the acuity test was used to evaluate the acquisition and retention of forehand drive in table tennis. This test was performed in this way that on the tennis table $50 \times 50$ squares was drowned. Inside these squares, three smaller $25 \times 25$ squares were placed (Figure 1). For each participant, 30 balls were sent ( 3 blocks, each block ten balls), and each person scored points concerning the area that returned the balls. Throwing the ball to area 1 , had 3 points, area 4, 2 points, other areas 1 point. The incorrect hit had no point. The subject's score in each block was calculated, and the average of blocks was recorded for each subject [22].

\section{Study design}

To examine changes in the perceptual-motor abilities of interest with ongoing practices, we used a pretestposttest design with four independent groups (VT, T, $\mathrm{V}, \mathrm{C}$ ). Following the pretest, the participants of VT, T, and $\mathrm{V}$ groups engaged in 12 sessions of different types of training. The control group did not participate in any practice session and was instructed to maintain their 


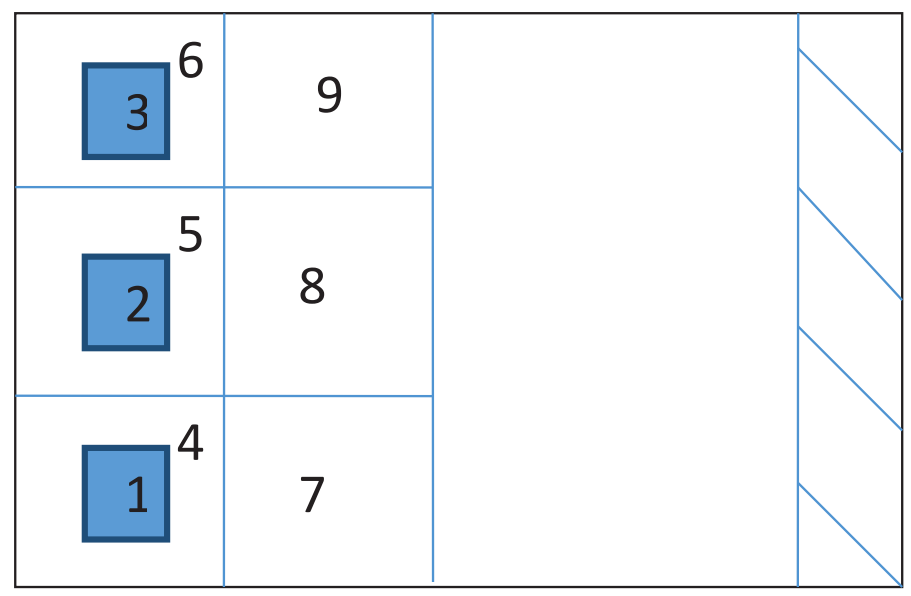

Figure 1. Tennis table scoring for the hitting acuity test

normal daily life. All the participants then performed a posttest.

\section{Study procedure}

To gather the required data, we initially evaluated the dominant eye, dominant hand, and the acuity of the participants. If the participants had the right dominant hands and eyes and possessed complete acuity (10/10), they were selected. Finally, 40 participants, who had successfully passed the previous stages, were selected to participate in the research study and were randomly assigned to four groups, each consisting of 10 members.

Before starting the exercises, the participants had to pass the pretest related to motor-perceptual abilities. Then, a practice session was considered for all the participants to get familiar with the ball, racket, and the correct method of holding the racket. Then, for the pretest, all participants were required to pass the test of forehand hitting accuracy. Then, all groups started their special exercises for four weeks, three sessions a week (in total, 12 sessions).

\section{Training protocol}

The participants of the VT group (visual-tennis group) received both visual training and forehand drive training of table tennis. The members of this group, in each week, received one session of training on forehand drive in table tennis and two sessions of visual training. In each session of training on forehand drive in table tennis, each participant performed 50 exercise trials, and in each session of visual training, 50 trials were done. For visual training, a computer program was used. To do this training, the participant sat in front of the computer screen. On the p.c. monitor, some arrows appeared randomly in different locations and directions. The participants were asked to follow the arrows with their eyes' quick movement and to press the button on the keyboard that showed the same direction that the arrow showed. This exercise was selected for improving the eye movements as the arrows appeared in all points of the p.c. screen. The number of correct and incorrect responses and the mean reaction time of each participant were recorded at the end of the exercise.

The visual training group (V) just received visual pieces of training. These members participated in three sessions of visual pieces of training each week. In each session, they performed 100 trials.

Tennis training group (T) just received training on table tennis forehand drive. They participated in three sessions each week. In each session, they received 100 training trials.

Tennis forehand drive training protocol was the same for all those who were trained.

The members of the control group (C) received no training or exercise.

After the specific training of each group was finished, all members participated in the motor-perceptual abilities posttest, and the test of evaluating table tennis forehand drive, performed in two stages. In the acquisition stage, all participants took the hitting precision test at the end of the exercises. For the retention stage, the same test was repeated $24 \mathrm{~h}$ later.

\section{Statistical analysis}

To evaluate the natural dispersion of data, the Shapiro Wilk test was done. The box's M test was performed to 
assess the presupposition of equality of the covariance matrix. To evaluate the presupposition of equality of variances, we performed the Levene's test. When there was a significant difference between groups, the ANCOVA was performed to control the pretest effect. LSD (Least Significant Difference) post hoc test was used to determine the group's mean difference. All statistical analysis was done by SPSS 19.

A factorial ANOVA (4*2) (group*time) and ANCOVA $(4 * 2)$ (group*time) were conducted with the repeated measurements analysis. The obtained data are reported as Mean \pm SD in the text and as Standard Error (SE) in Tables 1 and 2. Statistical significance was set at $\mathrm{P}<0.05$.

\section{Results}

In this experiment, all participants were inexperienced students from Shahid Beheshti University within the age range of 20 to 23 years. Table 1 presents the average age of each group. Tables 2 and 3 present the summary of the pretest and posttest results of each group and each research variable.

Since the difference among the groups in the pretest of forehand drive accuracy was significant $(\mathrm{F}=3.22$, $\mathrm{P}=0.03$ ), an ANCOVA (between-subjects factor: group [VT, V, T, C]; within-subject factor: time (pretest, posttest, and retention test; covariate: pretest scores of group * time) was conducted to determine a statistically difference between groups and times and the interaction between group by time on the number of forehand drive ac- curacy variable. The results of this test revealed that the main effects of group $(\mathrm{F}=274.1, \mathrm{P}=0.001, \mathrm{Eta}=0.88)$ or time $(\mathrm{F}=14.49, \mathrm{P}=0.001, \mathrm{Eta}=0.029)$ and the interaction between group and time $(\mathrm{F}=15.46, \mathrm{P}=0.001, \mathrm{Eta}=0.057)$ were significant (Table 4).

To detect the exact place of difference among the groups, we performed the LSD post hoc test. The results showed that the difference between the V and VT groups was significant and in favor of the VT $(\mathrm{M}=1.72$, $\mathrm{P}=0.001)$. The difference between the $\mathrm{C}$ and $\mathrm{VT}$ was significant and in favor of the VT $(\mathrm{M}=2.61, \mathrm{P}=0.02)$. The difference between the T and VT was significant and in favor of the combinational group ( $\mathrm{M}=1.07, \mathrm{P}=0.005)$. The difference between the $\mathrm{V}$ and control groups was significant, and the difference was in favor of the $\mathrm{V}$ $(\mathrm{M}=0.81, \mathrm{P}=0.02)$. There was no significant difference between the $\mathrm{V}$ and $\mathrm{T}$ groups $(\mathrm{M}=0.65, \mathrm{P}=0.07)$. The difference between the $\mathrm{T}$ and $\mathrm{C}$ groups was significant and in favor of the $\mathrm{T}$ group $(\mathrm{M}=1.54, \mathrm{P}=0.001)$. To detect the exact place of difference among times, we used the LSD post hoc test. The test results showed that the difference between the pretest and posttest was significant and in favor of the posttest $(\mathrm{M}=3.91, \mathrm{P}=0.001)$. The difference between retention and posttest was significant, and the difference was in favor of the posttest $(M=3.91$, $\mathrm{P}=0.001$ ). To detect the exact place of the differences between interaction effects, we conducted the LSD post hoc test. The obtained results showed that, in the posttest stage, the difference between the V and VT was significant and in favor of the VT group $(\mathrm{M}=5.17, \mathrm{P}=0.001)$. Moreover, in the posttest stage, the difference between

Table 1. Descriptive statistics of age (year) in each group of the experiment $(n=10)$

\begin{tabular}{cc}
\hline Group & Mean \pm SD \\
\hline V & $21.10 \pm 0.57$ \\
$V T$ & $21.60 \pm 0.97$ \\
$T$ & $21.70 \pm 0.82$ \\
C & $21.60 \pm 0.70$ \\
\hline
\end{tabular}

Table 2. The results of the pretest, posttest, and retention of forehand drive accuracy in table tennis $(\mathrm{n}=10)$

\begin{tabular}{|c|c|c|c|c|}
\hline \multirow{2}{*}{ Variable } & \multirow{2}{*}{ Groups } & \multicolumn{3}{|c|}{ MeanıSD } \\
\hline & & Pretest & Posttest & Retention \\
\hline \multirow{4}{*}{ Forehand drive } & $\mathrm{VT}^{*}$ & $7.10 \pm 2.60$ & $15.93 \pm 3.15$ & $15.78 \pm 3.69$ \\
\hline & V & $8.40 \pm 3.39$ & $11.33 \pm 2.41$ & $12.27 \pm 3.59$ \\
\hline & $\mathrm{T}$ & $8.27 \pm 1.23$ & $13.23 \pm 2.12$ & $13.70 \pm 2.18$ \\
\hline & $\mathrm{C}$ & $10.77 \pm 3.09$ & $9.70 \pm 2.76$ & $10.47 \pm 3$ \\
\hline
\end{tabular}

VT: visual and tennis training group; V: visual training group; T: tennis training group; C: control group. 
Table 3. The results of the pretest and posttest of motor-perceptual abilities $(n=10)$

\begin{tabular}{|c|c|c|c|}
\hline \multirow{2}{*}{ Variables } & \multirow{2}{*}{ Groups } & \multicolumn{2}{|c|}{ Mean $\pm S D$} \\
\hline & & Pretest & Posttest \\
\hline \multirow{4}{*}{ Reaction time } & $\mathrm{VT}^{*}$ & $0.44 \pm 0.07$ & $0.32 \pm 0.08$ \\
\hline & V & $0.48 \pm 0.06$ & $0.40 \pm 0.03$ \\
\hline & T & $0.51 \pm 0.06$ & $0.40 \pm 0.09$ \\
\hline & C & $0.49 \pm 0.06$ & $0.49 \pm 0.04$ \\
\hline \multirow{4}{*}{ Anticipation } & $\mathrm{VT}$ & $0.14 \pm 0.07$ & $0.08 \pm 0.03$ \\
\hline & $\mathrm{V}$ & $0.07 \pm 0.05$ & $0.03 \pm 0.01$ \\
\hline & T & $0.10 \pm 0.6$ & $0.07 \pm 0.07$ \\
\hline & C & $0.14 \pm 0.14$ & $0.17 \pm 0.08$ \\
\hline \multirow{4}{*}{ Eye-hand coordination (number of error) } & $\mathrm{VT}$ & $110.30 \pm 22.07$ & $89.10 \pm 14.50$ \\
\hline & $\mathrm{V}$ & $110.80 \pm 13.86$ & $77.70 \pm 12.96$ \\
\hline & $\mathrm{T}$ & $115 \pm 25.75$ & $101 \pm 26.28$ \\
\hline & C & $112.60 \pm 22.06$ & $106.50 \pm 23.46$ \\
\hline \multirow{4}{*}{ Eye-hand coordination (error time) } & VT & $6.73 \pm 23.13$ & $3.70 \pm 9.26$ \\
\hline & v & $5.53 \pm 11.91$ & $4.07 \pm 12.09$ \\
\hline & $\mathrm{T}$ & $6.38 \pm 32.24$ & $3.72 \pm 13.09$ \\
\hline & C & $8.68 \pm 13.72$ & $8.65 \pm 11.55$ \\
\hline \multirow{4}{*}{ Depth perception } & $\mathrm{VT}$ & $0.60 \pm 0.60$ & $0.52 \pm 0.38$ \\
\hline & v & $0.88 \pm 0.94$ & $0.35 \pm 0.30$ \\
\hline & $\mathrm{T}$ & $0.87 \pm 0.99$ & $0.43 \pm 0.94$ \\
\hline & $\mathrm{C}$ & $0.94 \pm 0.72$ & $1.11 \pm 1.19$ \\
\hline
\end{tabular}

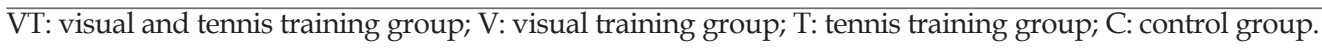

JMR

Table 4. Summary of ANCOVA results of forehand drive accuracy

\begin{tabular}{ccccc}
\hline Source & dfb/dfw & F & P & Eta \\
\hline Group & $3 / 36$ & 274.1 & 0.001 & 0.88 \\
Time & $3 / 36$ & 14.49 & 0.001 & 0.029 \\
Group*time & $3 / 36$ & 15.46 & 0.001 & 0.057 \\
\hline
\end{tabular}

$\mathrm{dfb}$ : degree of freedom between; dfw: degree of freedom within.

the $\mathrm{V}$ and $\mathrm{C}$ groups was significant, and the difference was in favor of the $\mathrm{V}$ group $(\mathrm{M}=2.67, \mathrm{P}=0.02)$. In the posttest stage, the difference between the $\mathrm{V}$ and $\mathrm{T}$ groups was not significant. The difference between the VT and $\mathrm{T}$ groups was significant and in favor of the VT group $(\mathrm{M}=3.21, \mathrm{P}=0.005)$. The difference between the $\mathrm{C}$ and $\mathrm{T}$ groups was significant and in favor of the $\mathrm{T}$ group $(\mathrm{M}=3.24, \mathrm{P}=0.001)$.

A $4 * 2$ ANOVA with group (VT, V, T, C) as a betweensubject factor and time (pretest and posttest) as a withinsubjects factor on the reaction time revealed the main effects of group $(\mathrm{F}=6.67$ and $\mathrm{P}=0.001)$, and time $(\mathrm{F}=67.25$ and $\mathrm{P}=0.001)$. These main effects were qualified by an interaction between group and time $(\mathrm{F}=10.02, \mathrm{P}=0.001)$ (Table 5).
To detect the exact place of difference among the groups, the LSD post hoc test was run. The obtained results revealed that the difference between the $\mathrm{V}$ and VT groups was significant and in favor of the $\mathrm{V}$ group $(\mathrm{M}=0.06, \mathrm{P}=0.01)$. The difference between the VT and $\mathrm{C}$ groups was not significant. The difference between the VT and $\mathrm{C}$ groups was significant, and this difference was in favor of the VT group ( $\mathrm{M}=0.112, \mathrm{P}=0.001)$. The difference between the $\mathrm{T}$ group and $\mathrm{C}$ group was not significant. To detect the exact place of the difference of interactional effect, we used the LSD post hoc test. The obtained results revealed that, in the pretest stage, there was not any significant difference among the groups. In the posttest stage, the difference between the V and VT groups was significant, and the difference was in favor of the $\mathrm{V}$ group $(\mathrm{M}=0.09, \mathrm{P}=0.004)$. Moreover, in the post- 
Table 5. Summary of ANOVA results of reaction time

\begin{tabular}{ccccc}
\hline Source & $\mathbf{d f b} / \mathbf{d f w}$ & $\mathbf{F}$ & $\mathbf{P}$ & \\
\hline Group & $3 / 36$ & 6.67 & 0.001 & 0.18 \\
Time & $3 / 36$ & 67.25 & 0.001 & 0.32 \\
Group*time & $3 / 36$ & 10.02 & 0.001 & 0.12 \\
\hline
\end{tabular}

$\mathrm{dfb}$ : degree of freedom between; dfw: degree of freedom within.

Table 6. Summary of ANOVA results of coincidence-anticipation timing accuracy

\begin{tabular}{ccccc}
\hline Source & $\mathbf{d f b} / \mathbf{d f w}$ & $\mathbf{F}$ & $\mathbf{P}$ & Eta \\
\hline Group & $3 / 36$ & 4.53 & 0.009 & 0.16 \\
Time & $3 / 36$ & 2.76 & 0.10 & 0.02 \\
\hline
\end{tabular}

$\mathrm{dfb}$ : degree of freedom between; dfw: degree of freedom within.

test stage, the difference between the $\mathrm{V}$ and $\mathrm{C}$ groups was significant, and in favor of the $\mathrm{V}$ group $(\mathrm{M}=0.08$, $\mathrm{P}=0.006$ ). In the posttest stage, the difference between the $\mathrm{V}$ and $\mathrm{T}$ groups was not significant. The difference between the $\mathrm{T}$ and $\mathrm{VT}$ groups was significant and in favor of the $\mathrm{T}$ group $(\mathrm{M}=0.08, \mathrm{P}=0.009)$. The difference between each of the $\mathrm{T}$ groups and $\mathrm{C}$ groups was significant, and the difference was in favor of the $\mathrm{T}$ groups $(\mathrm{P} \leq 0.05)$.

The difference of the mean of coincidence-anticipation timing accuracy scores among the groups, in the pretest phase, was not significant $(\mathrm{F}=1.28$ and $\mathrm{P}=0.29)$. Using multivariate variance analysis of $4 * 2$ (measurement stages* group), we evaluated the hypotheses related to the coincidence-anticipation timing accuracy. The obtained results revealed that the main effect of the group was significant $(\mathrm{F}=4.53, \mathrm{P}=0.009)$ (Table 6).

To detect the exact place of difference among groups, we conducted the LSD post hoc test. The obtained results revealed the significant difference between the visual and combinational groups and in favor of the combinational group $(\mathrm{M}=0.05, \mathrm{P}=0.48)$. The difference between the combinational and control groups was not significant. The difference between the skill group and the control group was significant and in favor of the skill group ( $\mathrm{M}=0.06, \mathrm{P}=0.02)$. The difference between the visual group and the control group was significant and in favor of the visual group ( $\mathrm{M}=0.11, \mathrm{P}=0.001)$. The results of this test showed that the main effect of measurement stages was not significant $(\mathrm{F}=2.76, \mathrm{P}=0.10)$. Moreover, significant results revealed the interactional effect of measurement stages with the groups $(\mathrm{F}=3.24, \mathrm{P}=0.03)$ (Table 6).

To detect the exact place of the difference of interactional effect, we conducted the LSD post hoc test. The obtained results revealed that, in the pretest stage, there was not any significant difference among the groups. In the posttest stage, there was a significant difference between the visual and combinational groups in favor of the visual group ( $\mathrm{M}=0.04, \mathrm{P}=0.047)$. Moreover, in the posttest stage, there was a significant difference between the visual and control groups in favor of the visual group $(\mathrm{M}=0.14, \mathrm{P}=0.001)$. In the posttest stage, the difference between the visual and skill groups was not significant. The difference between the combinational and skill groups was not significant. The difference between each of the three exercise groups was significant, and this difference was mainly in favor of the exercise groups $(\mathrm{P} \leq 0.05)$.

Since the difference among the groups in the pretest of eye-hand coordination was significant $(\mathrm{F}=3.70, \mathrm{P}=0.02)$, using multivariate variance analysis of $4 * 2$ (measurement stages* group), we evaluated the hypotheses related to the eye-hand coordination. The scores of the pretest of eye-hand coordination were used as the covariance factor. The results of this test revealed that the main effect of the group was significant $(\mathrm{F}=45.46, \mathrm{P}=0.001)$ (Table 7).

To detect the exact location of the difference among groups, we used the LSD post hoc test. The results of the test revealed a significant difference between the visual and combinational groups in favor of the combinational group $(\mathrm{M}=4.02, \mathrm{P}=0.04)$. There was a significant difference between the control and combinational groups in favor of the combinational group ( $\mathrm{M}=21.61, \mathrm{P}=0.001)$. The difference between the combinational and skill groups was not significant. The difference between the visual and control groups was significant and in favor of the visual group $(\mathrm{M}=17.17, \mathrm{P}=0.001)$. There was not a difference between the visual and skill groups. The difference between the skill and control groups was significant and in favor of the skill group $(\mathrm{M}=21.19, \mathrm{P}=0.001)$. 
Table 7. Summary of ANOVA results of eye-hand coordination

\begin{tabular}{ccccc}
\hline Source & dfb/dfw & F & P & \\
\hline Group & $3 / 36$ & 45.46 & 0.001 & 0.79 \\
Time & $3 / 36$ & 95.16 & 0.001 & 0.73 \\
Group*time & $3 / 36$ & 46.46 & 0.001 & 0.76 \\
\hline
\end{tabular}

$\mathrm{dfb}$ : degree of freedom between; dfw: degree of freedom within.

Table 8. Summary of ANOVA results of depth perception

\begin{tabular}{ccccc}
\hline Source & $\mathbf{d f b} / \mathbf{d f w}$ & $\mathbf{F}$ & $\mathbf{P}$ & Eta \\
\hline Group & $3 / 36$ & 0.99 & 0.40 & 0.09 \\
Time & $3 / 36$ & 2.19 & 0.14 & 0.03 \\
Group*time & $3 / 36$ & 1.20 & 0.33 & 0.06 \\
\hline
\end{tabular}

$\mathrm{dfb}$ : degree of freedom between; dfw: degree of freedom within.

The results of the test showed that the main effect of measurement stages was significant $(\mathrm{F}=95.16, \mathrm{P}=0.001$, $\mathrm{Eta}=0.73)($ Table 7). The difference between the pretest and posttest was significant and in favor of the posttest $(\mathrm{M}=17.94, \mathrm{P}=0.001)$. Moreover, significant results showed the interactional effects of measurement stages with two groups $(\mathrm{F}=46.46, \mathrm{P}=0.001$, $\mathrm{Eta}=0.76)$ (Table 7). To determine the exact difference location among interactional effects, we used the LSD post hoc test. The test results revealed that, in the posttest stage, the difference between visual and combinational groups was significant and in favor of the combinational group $(\mathrm{M}=8.04, \mathrm{P}=0.04)$. Moreover, in the posttest stage, the difference between the visual and control groups was significant and in favor of the visual group $(\mathrm{M}=34.34$, $\mathrm{P}=0.001$ ). In the posttest stage, the difference between the visual and skill groups was not significant. The difference between the combinational and skill groups was not significant. The difference between skill and control groups was significant, and in favor of the skill group $(\mathrm{M}=40.83, \mathrm{P}=0.001)$.

The difference in the pretest scores of the depth perception was not significant among the groups $(\mathrm{F}=0.33$, $\mathrm{P}=0.80$ ). Using multivariate variance analysis of $4 * 2$ (measurement stages* group), we evaluated the hypotheses related to the depth perception. The results of this test revealed that the main effect of the group was not significant $(\mathrm{F}=0.99, \mathrm{P}=0.40)$. The results also revealed that the main effect of measurement stages was not significant $(\mathrm{F}=2.19, \mathrm{P}=0.14)$. The results also showed that the interactional effects of the measurement stages with the group was not significant, too $(\mathrm{F}=1.20, \mathrm{P}=0.33)$ (Table 8).

\section{Discussion}

One of the aims of the present research study was to evaluate the impacts of visual and skill training on the acquisition and retention of forehand skills in table tennis players. The findings of this study showed that visual training, along with table tennis training resulted in significant improvement in the acquisition and retention of the forehand drive. the findings of this study are consistent with the findings of West and Berson [16], Williams et al. [23], du Toit et al. [18]. Similar to the current research, they reported that visual and cognitive training could improve different motor skills such as Cricket and Hockey.

According to Wilson and Falkel, the saccadic movements of the eye are among the motor skills of the visual sense that are very important both in sports and in daily life [22]. Moreover, the eye saccadic movements are vital in table tennis [5]. Researchers have demonstrated that the motor skills of the visual sense are improved through practice, and this improvement results in appropriate motor functions during the performance of sport exercises [5]. Through practice, the control system can produce faster saccadic movements regarding the predictable direction. Generally, motor preparation of the eye saccadic system may become shorter after the exercises, and this improvement in the eye saccadic movements may lead to the improvement of motor function [17].

Some researchers believe that visual training in the improvement of cognitive function in attention exercises is useful because the cortical network is responsible for attention, recognition, and eye movement and is probably faced with short-term neural figure-ground perception. Moreover, eye saccadic movements can significantly increase the attention control. Krzepota et al argued that 
eye saccadic movements from one point to another require the production of active energy by the eye muscles, and visual training can help this matter [24]. Moreover, it has been said that the repetition of the visual system exercises can create stronger muscular fibers, and more efficient neural reactions and athletes with stronger saccadic reactions can follow the ball path sooner and more accurately [1].

As the results of the study revealed, the interactional effects of visual and athletic exercises on the acquisition and retention of forehand drive in table tennis were more than the effect of athletic and visual training in separation. So, perhaps it is possible to claim that the performance of athletic activities, along with visual training, can significantly affect acquisition and learning. Moreover, the separation of some of the visual-perceptual parts from the professional components of athletic skills for the performance of visual training causes the perception-performance coupling to face a problem. This separation damages the specialization principle of the exercise and, consequently, is impractical [25]. Therefore, for the greater effectiveness of visual training, it should be accompanied by skill training. The recognition and detection of the specific visual skill that is specific to each athletic field is an important factor that should be taken into consideration. Thus, the selection of correct visual training based on the required visual skills in each sport can improve sports performance.

Another aim of the research was to evaluate the effect of skill and visual training on motor-perceptual abilities. Our results indicate that the visual training results in the improvement of the reaction time, adaptive scheduling prediction, and eye-hand coordination (error numbers and error time). However, visual training did not affect depth perception. These findings are in line with the findings of Williams et al. [23], Di Rouso et al. [17], and Paul et al. [2].

The motor-perceptual abilities evaluated in the present research study were visual reaction time, adaptive scheduling prediction, eye-hand coordination, and depth perception. The vision sense plays a vital and significant role in these abilities. Even some researchers have considered the reaction time and eye-hand coordination as visual skills and depth perception as one of the visual abilities. Moreover, the prediction is a visual-perceptual skill in which vision plays a significant role.

Considering the difference between the visual skills and visual abilities and how they affect the actions directed and controlled by the sense vision is very helpful to explain our findings, which showed that depth perception was not improved after training sessions. Cavai nagh described the visual abilities as the fixed general features of the visual system and stated that visual abilities do not encompass the cognitive element, but rather, they involve the data gathering process. However, visual skills involve a cognitive element and include visual data perception [26]. Therefore, depth perception is regarded as an ability, not a skill, and exercise has not been effective in developing depth perception. Moreover, it was mentioned that visual function in sport is the result of interaction between the two hardware and software visual systems.

Hardware visual systems have been recognized as the physical, mechanical, and optometric features of the visual system. When the cognitive processes are matched with the visual data, the term "software" is used for the description of a set of visual perceptual skills [27]. According to Williams, the skills that are required for making correct and accurate decisions in the sport environments are the software system skills [23]. Although the visual-perceptual skills of the software system may be limited by the visual abilities of the hardware system and cognitive growth, these skills can be improved through learning, experience, and visual training programs [27]. Moreover, researchers believe that the hardware system refers to the structural features of the visual system that encompasses some fundamental visual abilities, and its change is either difficult or impossible. Thus, motor-perceptual abilities evaluated in this study are among the visual perceptual skills, and they can be improved through visual training. Depth perception, however, is a visual ability whose change is impossible.

Another important point in this study is the significant improvement of some motor-perceptual abilities in the group of sport exercises. Eye-hand coordination, reaction time, and the prediction had significantly increased in the groups that had practiced the forehand drive in table tennis. So, some of the visual-perceptual skills can be improved through specific sport exercises. Forehand drive skill in table tennis seriously requires hand-eye coordination, rapid reaction, and an accurate prediction that the findings of the present study also confirm this result. Therefore, research findings support the feature hypothesis. Based on this hypothesis, the visual involvement of any athlete depends on the environmental needs and the type of sport. Each sport skill and field requires its own peculiar visual skills $[28,29]$. 


\section{Conclusion}

Considering the obtained results, visual training, along with skill training, has been influential in learning motor skills as well as reaction time, prediction, and hand-eye coordination. It is suggested that coaches and athletes use visual training as a complement for skill training to achieve appropriate optimal performance and function and take benefit from these exercises.

\section{Ethical Considerations}

\section{Compliance with ethical guidelines}

The Ethics Committee of Shahid Beheshti University (Code: IR.SBU.REC.1396.002) approved the study. All participants filled a written consent form and were free to leave the study at any stage.

\section{Funding}

The paper extracted form the thesis of the first author.

\section{Authors contributions}

Conceptualization, Methodology, Investigation, Resources, and Funding Acquisition: all author; Writing original draft: Fahime Basiri, Maryam Kavyani; Writingreview and editing: Maryam Kavyani; Supervision: Alireza Farsi and Maryam Kavyani.

\section{Conflict of interest}

The authors declared no conflict of interest.

\section{References}

[1] Magill R, Anderson D. Motor learning and control: Concepts and applications. $10^{\text {th }}$ ed. New York City: McGrawHill Higher Education; 2013. https://books.google.com/ books?id=KXYgAAAAQBAJ\&dq

[2] Paul M, Biswas SK, Sandhu JS. Role of sports vision and eye hand coordination training in performance of table tennis players. Brazilian Journal of Biomotricity. 2011; 5(2):106-16. https://www.researchgate.net/publication/228488499

[3] Jerath R, Crawford MW, Barnes VA. Functional representation of vision within the mind: A visual consciousness mode based in 3D default space. Journal of Medical Hypotheses and Ideas. 2015; 9(1):45-56. [DOI:10.1016/j.jmhi.2015.02.001]

[4] Christenson GN, Winkelstein AM. Visual skills of athletes versus nonathletes: Development of a sports vision testing battery. Journal of the American Optometric Association. 1988; 59(9):666-75. https://psycnet.apa.org/record/1989-21075-001
[5] Erickson GB, Citek K, Cove M, Wilczek J, Linster C, Bjarnason B, et al. Reliability of a computer-based system for measuring visual performance skills. Optometry - Journal of the American Optometric Association. 2011; 82(9):528-42. [DOI:10.1016/j.optm.2011.01.012] [PMID]

[6] Seidel O, Ragert P. Effects of transcranial direct current stimulation of primary motor cortex on reaction time and tapping performance: A comparison between athletes and non-athletes. Frontiers in Human Neuroscience. 2019; 13:103. [DOI:10.3389/fnhum.2019.00103] [PMID] [PMCID]

[7] Cross ES, Stadler W, Parkinson J, Schütz $\square$ Bosbach S, Prinz $\mathrm{W}$. The influence of visual training on predicting complex action sequences. Human Brain Mapping. 2013; 34(2):467-86. [DOI:10.1002/hbm.21450] [PMID]

[8] Abernethy B. Training the visual-perceptual skills of athletes: Insights from the study of motor expertise. The American Journal of Sports Medicine. 1996; 24(6_suppl):S89-S92. [DOI:10.1177/036354659602406S24]

[9] Tate B, Paul M, Jaspal S. The impact of visual skills training program on batting performance in cricketers. Serbian Journal of Sports Sciences. 2008; 2(1):17-23. https://www. sjss.sportsacademy.edu.rs/archive/details/the-impact-ofvisual-skills-training-program-on-batting-performance-incricketers-23.html

[10] Çetin O, Beyleroğlu M, Bağış Y, Suna G. The effect of the exercises brain on boxers eye-hand coordination, dynamic balance and visual attention performance. Physical Education Of Students. 2018; 22(3):112-9. [DOI:10.15561/20755279. 2018.0301]

[11] Kluka DA. Visual skills: Considerations in learning motor skills for sport. ASAHPERD Journal. 1991; 14(1):41-3. https:/ scholar.google.com/scholar?hl=en\&as_sdt $=0 \% 2 \mathrm{C} 5 \& \mathrm{q}=\mathrm{Kluk}$ $\mathrm{a}+\mathrm{D}$.+Visual+skills $\% 3 \mathrm{~A}+$ Considerations+in+learning+motor +skills+for+sport.+Asahperd+Journal.+1991\%3B+14\%281\%2 9\%3A41-3.\&btnG=

[12] Pizzera A, Raab M. Perceptual judgments of sports officials are influenced by their motor and visual experience. Journal of Applied Sport Psychology. 2012; 24(1):59-72. [DOI:10.1080 /10413200.2011.608412]

[13] Stine CD, Arterburn MR. Vision and sports: A review of the literature. Journal of the American Optometric Association. 1982; 53(8):627-33. [PMID]

[14] Wood Joanne M, Abernethy B. An assessment of the efficacy of sports vision training programs. Optometry and Vision Science. 1997; 74(8):646-59. [DOI:10.1097/00006324199708000-00026] [PMID]

[15] Abernethy B, Wood JM. Do generalized visual training programmes for sport really work? An experimental investigation. Journal of Sports Sciences. 2001; 19(3):203-22. [DOI:10. 1080/026404101750095376] [PMID]

[16] West K, Bressan E. The effects of a general versus specific visual skills training program on accuracy in judging lengthof-ball in cricket. International Journal of Sports Vision. 1996; 3(1):41-5. https://scholar.google.com/scholar?hl=en\&as_ $\mathrm{sdt}=0 \% 2 \mathrm{C} 5 \& \mathrm{q}$

[17] Di Russo F, Pitzalis S, Spinelli D. Fixation stability and saccadic latency in elite shooters. Vision Research. 2003; 43(17):1837-45. [DOI:10.1016/S0042-6989(03)00299-2] 
[18] du Toit PJ, Krüger PE, Fowler KF, Govender C, Clark J. Influence of sports vision techniques on adult male rugby players. African Journal for Physical Activity and Health Sciences. 2010; 16(3):510-7. [DOI:10.4314/ajpherd.v16i3.60931]

[19] Hopwood MJ, Mann DL, Farrow D, Nielsen T. Does visual-perceptual training augment the fielding performance of skilled cricketers? International Journal of Sports Science \& Coaching. 2011; 6(4):523-35. [DOI:10.1260/1747-9541.6.4.523]

[20] Abernethy B. Selective attention in fast ball sports. II: Expert novice differences. Australian Journal of Science and Medicine in Sport. 1987; 19(4):7-16. https://espace.library. uq.edu.au/view/UQ:276055

[21] Knoblich G, Flach R. Predicting the effects of actions: Interactions of perception and action. Psychological Science. 2001; 12(6):467-72. [DOI:10.1111/1467-9280.00387] [PMID]

[22] Wilson TA, Falkel J. SportsVision: Training for better performance. Champaign, IL: Human Kinetics; 2004. https:// books.google.com/books?id=8AMHnqQHWBYC\&dq

[23] Williams AM, Ward P, Knowles JM, Smeeton NJ. Anticipation skill in a real-world task: measurement, training, and transfer in tennis. Journal of Experimental Psychology Applied. 2002; 8(4):259-70. [DOI:10.1037/1076-898X.8.4.259] [PMID]

[24] Krzepota J, Zwierko T, Puchalska-Niedbał L, Markiewicz M, Florkiewicz B, Lubiński W. The efficiency of a visual skills training program on visual search performance. Journal of Human Kinetics. 2015; 46:231-40. [DOI:10.1515/ hukin-2015-0051] [PMID] [PMCID]

[25] Turvey M, Carello C. The ecological approach to perceiving-acting: A pictorial essay. Acta Psychologica. 1986; 63(13):133-55. [DOI:10.1016/0001-6918(86)90060-0]

[26] Cavanagh P. Visual cognition. Vision Research. 2011; 51(13):1538-51. [DOI:10.1016/j.visres.2011.01.015] [PMID] [PMCID]

[27] Campher J. The role of visual skills and its impact on skill performance of cricket players [MSc. thesis]. Pretoria: University of Pretoria; 2009. https://repository.up.ac.za/handle/2263/28869

[28] Yuan Y, Xu F, Chin MK, So R. Hand-eye co-ordination and visual reaction time in elite badminton players and gymnasts. New Zealand Journal of Sports Medicine. 1995; 23:19. https://scholar.google.com/scholar?hl=en\&as_sdt $=0 \% 2 \mathrm{C} 5 \& \mathrm{q}$

[29] Davlin CD, Sands WA, Shultz BB. The role of vision in control of orientation in a back tuck somersault. Motor Control. 2001; 5(4):337-46. [DOI:10.1123/mcj.5.4.337] [PMID] 
This Page Intentionally Left Blank 